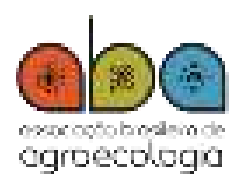

ISSN: 1980-9735

DOI: $10.33240 /$ rba.v16i2.23200

Vol. 16 | No 2 | p.156-168 | 2021

\title{
CARACTERIZAÇÃO AGROECOLÓGICA DE SISTEMAS TRADICIONAIS DE PRODUÇÃO DO AÇAÍ (EUTERPE SPP.) EM CARAUARI, NO MÉDIO RIO JURUÁ, ESTADO DO AMAZONAS \\ Agroecological characterization of traditional açaí (Euterpe spp.) production systems in Carauari, in the middle Juruá river, state of Amazonas
}

\author{
Jhassem Antônio Silva de Siqueira ${ }^{1}$, Henrique dos Santos Pereira², Suzy Cristina Pedroza da
} Silva $^{3}$ e Maria Luiza de Azambuja Midosi Ricart ${ }^{4}$

1 Doutor em Ciências do Ambiente e Sustentabilidade na Amazônia pela Universidade Federal do Amazonas. Email: siqueirajhassem@gmail.com

2 Doutor pela The Pennsylvania State University. E-mail:

henrique.pereira.ufam@gmail.com

${ }^{3}$ Doutora em Geociências Aplicadas pela Universidade de Brasilia. E-mail suzyycris@gmail.com

${ }^{4}$ Especialização em engenharia ambiental pela Universidade Federal do Amazonas. E-mail

mluizaricart@gmail.com

Recebido em: 01/04/2020

Aceito para publicação em: 08/8/2020

Correspondência para: siqueirajhassem@gmail.com

\section{RESUMO}

Em Carauari, a coleta extrativa e o cultivo do açaí (Euterpe spp.) resultam do manejo complexo de agroecossistemas que diferem em seus aspectos sociais e organizacionais. Para descrever os padrões de organização agroecológica desses diferentes agroecossistemas produtores de açaí, foram realizados levantamentos dendrométricos e edafológicos, para caracterização das estruturas das populações de Euterpe spp., suas distribuição e interação nos sistemas ambientais e sociais locais. Os levantamentos foram conduzidos em três territórios coletivos: Projeto de Assentamento Riozinho, na Reserva Extrativista Médio Juruá; e na Reserva de Desenvolvimento Sustentável de Uacari. Os açaizais ocorrem em ambiente de terra firme ou em áreas próximas de corpos d'água, sob a forma de floresta extrativa de $E$. precatoria ou de sistemas cultivados. Esses últimos podem ser monocultivos, consórcios entre as espécies Euterpe oleraceae e Euterpe precatoria, ou sistema agroflorestal com outras espécies de frutíferas e madeireiras, associadas ou não com a criação de animais. Esses agroecossistemas geram significados econômicos e culturais importantes, além de estruturarem as paisagens locais.

Palavras-chave: Inventário. Solo. Unidades de conservação. Projeto de assentamento.

\section{ABSTRACT}

In Carauari, the extractive collection and cultivation of açaí (Euterpe spp.) Results from the complex management of agroecosystems that differ in their social and organizational aspects. To describe the patterns of agroecological organization of these different agroecosystems that produce açaí, dendrometric and soil surveys were carried out to characterize the structures of the populations of Euterpe spp., Their distributions and interactions in the local environmental and social systems. The surveys were conducted in three collective territories: Riozinho Settlement Project, Medium Juruá Extractive Reserve and Uacari Sustainable Development Reserve. Açaizais occur in dryland environments or in areas close to water bodies, in the form of native extractive forest of E. precatoria or cultivated systems. The latter can be monocultures, consortia between the species E. oleraceae and E. precatoria, or agroforestry systems with other species of fruit and timber, associated or not with animal husbandry. These agroecosystems generate important economic and cultural meanings, in addition to structuring local landscapes

Keywords: Inventory. Soil. Conservation Units. Settlement Project. 


\section{Introdução}

A sociedade global encontrou na região amazônica um ambiente propício e desafiador para a construção de novos paradigmas de desenvolvimento socioeconômico que considerem as relações sistêmicas. A conservação da biodiversidade das florestas tropicais está na base desse desafio e envolve a complexidade das dimensões ecológicas, econômicas, tecnológicas, sociopolíticas, éticas e epistemológicas dessas relações (BECKER, 2001).

O produtor rural de comunidades tradicionais é um dos componentes vitais para a manutenção das características da fitofisionomia do ambiente florestal na Amazônia. Dentre os produtos dos agroecossistemas amazônicos de maior destaque no mercado, nos últimos anos, está o açaí, uma fruta de cor violácea, oriunda de uma espécie de palmeira (Euterpe spp.) originária da Amazônia. Esse fruto vem, ao longo dos séculos, compondo uma parte fundamental da dieta local e uma importante referência cultural para grande parte da população amazônica. O açaí é, tradicionalmente, consumido como bebida preparada com polpa fresca diluída em água que, na região, é chamado de "vinho" (não alcoólico) de açaí. A maior parcela da produção e do consumo brasileiro permanece no estado do Pará, no entanto, outros estados como Amazonas e Amapá também produzem e consomem significativas quantidades (PEGLER, 2015).

No estado do Amazonas, apesar da intensificação do plantio de açaí em áreas de agricultura familiar e, mais recentemente em plantios agroindustriais, a parcela da produção, originada pela exploração de açaizais em áreas de floresta, ainda responde por $90 \%$ das safras anuais (MARTINOT, 2013). Os açaizais nativos são ambientes de florestas de várzea ou terra firme, com maior densidade da espécie, igualmente ricos e distintos, como outras áreas de florestas nativas no que se refere à biodiversidade, com potencial produtivo a partir do uso madeireiro, de palmito, frutos diversos, essências aromáticas, sementes oleaginosas e manejo de fauna. Esses ecossistemas amazônicos vêm passando por práticas de manejo humano desde o holoceno (MAGALHÃES, 2016), praticado por populações locais integradas ao ambiente.

O açaí passou a ter uma maior difusão no mercado brasileiro, a partir dos anos 2000, devido à propagação de suas propriedades nutritivas, consequentemente, sua demanda cresceu. Como reflexo, as exportações começaram a ser significativas e vêm crescendo a um ritmo acelerado desde então. No entanto, a cadeia de valor do açaí é complexa, com reflexo no risco de saúde física na realização do trabalho de coleta manual dos cachos, mediante a escalada das árvores nas áreas de produção (MARTINOT, 2013). Além desse, outros gargalos também se encontram ao longo da cadeia produtiva (PEGLER, 2015), como por exemplo, a falta de conhecimento sobre as características dos diferentes ambientes tradicionais de produção do fruto.

A partir de 2010, a participação do estado do Amazonas no mercado de açaí começou a ser relevante. Entre os anos de 2000 a 2010, o Amazonas comercializou um total de 15.061 toneladas de açaí. Surpreendentemente, entre 2011 a 2013 esse número atingiu 232,409 toneladas (IBGE, 2015). Esse crescimento representa o resultado da inserção do produto local nos mercados nacionais e internacionais. O município de Carauari, na região do Médio rio Juruá, participou efetivamente da ascensão da produção no Amazonas. Após o ápice da produção no ano de 2011, registrou uma queda nos anos seguintes, ascendendo, novamente, nos anos de 2016 e 2017. Esse fato resulta em propriedades emergentes nas relações sistêmicas no ambiente de produção do fruto.

O município de Carauari está localizado numa das porções mais bem conservadas da região amazônica, a bacia do rio Juruá, situado no noroeste do Estado do Amazonas. Em Carauari, assim como em outras localidades em que predominam os modos tradicionais de produção, os agentes sociais locais agem em rede, com base em seu capital social, estabelecem características de complementaridade com o ambiente e moldam as paisagens florestadas, constituintes dos agroecossistemas (DERICKX, 1993; ITABORAHY, 2009; SIQUEIRA, 2018). 
As atuais estratégias de produção das cadeias do agroextrativismo do açaí em Carauari envolvem a participação de organizações de agricultores familiares tradicionais e de outros setores do agronegócio, que interagem, resultando em diferentes técnicas de manejo do fruto de açaí. Essa interação gera paisagens específicas, associadas não apenas às florestas extrativas de açaí silvestre e outros produtos florestais, mas, também, às paisagens modificadas pela implementação de outros cultivos agrícolas, corroborando as afirmações de Balée (1987) e Levis et al., (2018), que consideram a floresta Amazônica como um artefato humano.

Nos cultivos agrícolas tradicionais em Carauari, a produção de açaí se destaca nos sistemas agroflorestais, onde são plantados, conjuntamente, em linha com outras espécies frutíferas, madeireiras e na presença de animais em áreas de terra firme. Nesse sistema, a Euterpe é intercalada com outras palmeiras, como a pupunheira (Bactris $s p$ ) e tucumanzeiro (Astrocaryum vulgare Mart.), também são plantadas as frutíferas herbáceas como o abacaxi (Ananas comosus (L.) Merril), as frutíferas arbóreas como a mangueira (Mangifera indica), o cupuaçuzeiro (Theobroma grandiflorum) e abacateiro (Persea americana), além de árvores madeireira como a andiroba (Carapa sp), geralmente utilizadas para a produção de óleo vegetal. Nesse sistema, verifica-se que a maior fonte de renda é a partir da comercialização do açaí, da manga e do abacaxi, para a agroindústria local.

Este artigo visa caracterizar os padrões de organização da estrutura populacional e parâmetros edafológicos dos diferentes sistemas de produção do açaí no Médio Juruá no Estado do Amazonas. Para isso, serão identificadas as características dos indivíduos de Euterpe spp., suas formas de distribuição e interação nos ambientes, além de citar as principais organizações sociais envolvidas na cadeia produtiva do açaí, caracterizando, assim, as emergências do sistema ambiental, em estruturas multiniveladas de sistemas dentro de sistemas, ou seja, partes do todo que compõem os agroecossistemas produtivos no município de Carauari.

\section{Metodologia}

O estudo ocorreu em três territórios geográficos coletivos do município de Carauari, sendo estes: Projeto de Assentamento Riozinho (PA Riozinho), na sede de Carauari; Reserva Extrativista Médio Juruá (RESEX Médio Juruá), localizada à margem esquerda do Rio Juruá; e a Reserva de Desenvolvimento Sustentável de Uacari (RDS de Uacari), também localizada às margens do rio Juruá (Figura 1).

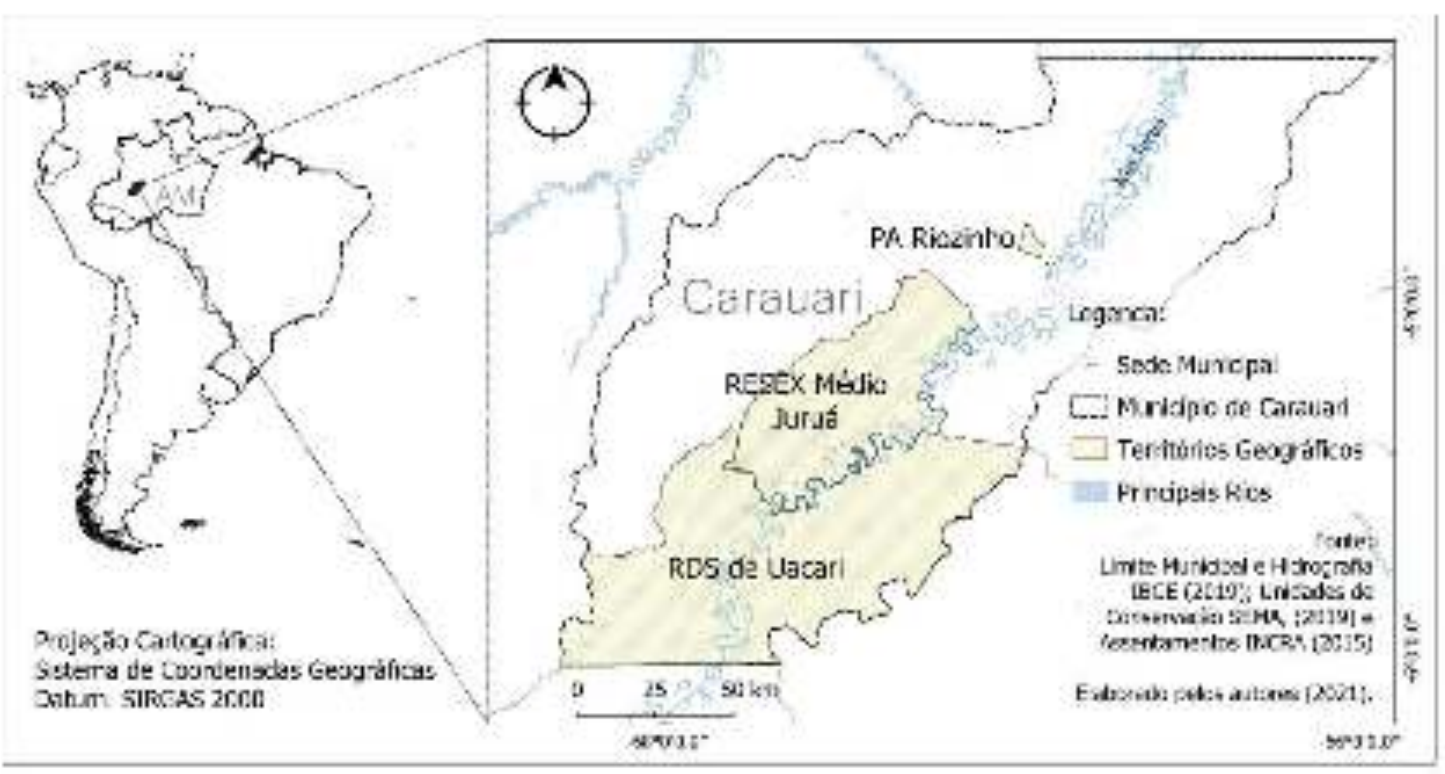


Figura 1. Localização das áreas do estudo de caracterização agroecológica da produção de açaí no Projeto de Assentamento (PA Riozinho), na Reserva Extrativista (RESEX Médio Juruá) e na Reserva de Desenvolvimento Sustentável (RDS de Uacari), no município de Carauari, no estado Amazonas, Brasil, nos anos de 2016/2017. Siglas: IBGE - Instituto Brasileiro de Geografia e Estatística; SEMA - Secretaria de Estado do Meio Ambiente do Estado do Amazonas, e INCRA Instituto Nacional de Colonização e Reforma Agrária.

O PA Riozinho está conectado à sede de Carauari, por meio de uma estrada com o mesmo nome que o do assentamento. Esse território é um assentamento federal e faz parte do Programa Nacional de Reforma Agrária (PNRA) de gestão do Instituto Nacional de Colonização e Reforma Agrária (INCRA). O Projeto de Assentamento ocupa uma área de 4.462, 21 hectares.

A RESEX Médio Juruá é uma unidade de conservação federal de gestão do Instituto Chico Mendes de Conservação da Biodiversidade (ICMBio) e possui uma extensão de 253.226, 5 hectares e tem um perímetro de 348.029,65 metros. A RDS Uacari é uma área protegida, na categoria de unidade de conservação de uso sustentável estadual, sob a gestão da Secretaria de Estado do Meio Ambiente (SEMA), ocupando uma área de 632.949,023 hectares.

Para os registros das estruturas dos ambientes dos açaizais, foram realizadas análises de solos e das populações de Euterpe (E. precatoria e E. oleraceae) nas diferentes áreas. As coletas de solo ocorreram ao longo de 2016 e 2017. Ao todo, foram coletadas oito amostras no Projeto de Assentamento Riozinho, em área de consórcio de espécies de açaí e em área de sistema agroflorestal (SAF), com a presença de açaí, ainda na Reserva Extrativista Médio Juruá e na Reserva de Desenvolvimento Sustentável de Uacari. O levantamento ocorreu nas florestas extrativas de açaí, sendo essas áreas de uso comum na RESEX pelas comunidades de: São Raimundo, Pupuaí, Nova União, Imperatriz e Tabuleiro. Na Reserva de Desenvolvimento Sustentável de Uacari, o levantamento também se deu nas áreas de floresta extrativa de açaí de uso comum pela comunidade Santo Antônio do Brito.

Cada amostra foi composta por subamostras de solo misto, coletadas aleatoriamente em cada área de ocorrência de açaizal, a uma profundidade de $20 \mathrm{~cm}$ (WADT et al., 2015). Empregou-se o método em ziguezague, onde as subamostras foram misturadas homogeneamente. A amostragem de superfície ( 10 a $20 \mathrm{~cm}$ de profundidade) é o método mais comumente utilizado para avaliar os nutrientes do solo disponíveis às plantas (MORAN, 2010, p.104).

As amostras de solo foram analisadas no Laboratório de Solos da Faculdade de Ciências Agrárias na Universidade Federal do Amazonas, segundo metodologia proposta por Silva (2009). Para determinação do $\mathrm{pH}$ - Acidez ativa $\left(\mathrm{CaCl}^{2}\right)$ e $\mathrm{H}+\mathrm{Al}-$ Acidez potencial (SMP) (cmolc dm${ }^{-3}$ ), foi utilizada a metodologia proposta por Van Raij et al. (2001).

Para análise da fitossociologia nos açaizais, foram realizados quatro (4) inventários florestais amostrais, em três comunidades, sendo dois inventários em lotes no Assentamento Riozinho, e dois nas duas unidades de conservação de uso sustentável. Nas unidades de conservação, um inventário ocorreu na comunidade São Raimundo, localizada na Reserva Extrativista Médio Juruá, e outro na comunidade Vila Ramalho, localizada na Reserva de Desenvolvimento Sustentável de Uacari.

A coleta de dados dos inventários se deu em unidades amostrais, em forma conglomerada de quatro parcelas, denominada Cruz de Malta, onde cada parcela representa uma área de 0,25 hectare, perfazendo o total de um (1) hectare em cada área inventariada (NETTO, 1971). A distância de cada parcela em relação ao ponto central do conglomerado foi de $10 \mathrm{~m}$. Nos três territórios de estudo, foram delimitadas um total de 16 parcelas, medindo $20 \times 125$ metros, totalizando $40.000 \mathrm{~m}^{2}$ (4 hectares) de açaizais inventariados nas áreas de estudos.

As parcelas foram estabelecidas em conglomerado e distribuídas nos três sistemas de manejo das espécies de Euterpe identificados em campo. Um conglomerado foi alocado em cada uma das seguintes áreas: sistema consorciado de Euterpe, no Assentamento Riozinho; sistema agroflorestal, também no PA Riozinho; na floresta extrativa, na Reserva Extrativista Médio Juruá; e na floresta extrativa, na Reserva de Desenvolvimento Sustentável de Uacari.

Foram registrados todos os indivíduos que apresentavam diâmetro à altura do peito (DAP) a partir de $5 \mathrm{~cm}$. Além dos inventários florestais, foram realizadas entrevistas junto aos produtores, 
para identificar outras características dos agroecossistemas amazônicos. A partir do roteiro de entrevista, pode-se obter, também, o diagnóstico socioeconômico destes produtores.

Para a verificação das características dendrométricas, optou-se pela técnica da análise por intervalo de confiança, com amostras independentes, sendo experimentos inteiramente ao acaso, em esquema fatorial com duas espécies (E. precatoria e E. oleraceae) e três (3) tipos de ambientes, sendo eles: consórcio, sistema agroflorestal e floresta extrativa.

Para a análise estatística, partiu-se do conhecimento de que os indivíduos observados pertencem a diversos grupos e procura-se determinar funções das variáveis observadas que melhor permitam distinguir ou discriminar entre esses grupos ou classes (TRIOLA, 1999).

Foram conduzidas três análises, de modo que foi possível observar a diferença entre as duas espécies nos diferentes cultivos no Assentamento Riozinho, além da diferença no desenvolvimento da E. precatoria nas duas florestas extrativas nas unidades de conservação, bem como da diferença da estrutura populacional da E. precatoria nas quatro áreas inventariadas.

Para avaliar a variação na relação entre diâmetro e altura dos estipes das palmeiras de açaí nos diferentes sistemas de produção, foi feita uma análise gráfica exploratória, a partir do gráfico de dispersão.

Também foi utilizado um roteiro de entrevista junto aos produtores, para obter informações sobre seus sistemas de produção e conhecimento a respeito dos agroecossistemas locais, além de informações sobre as organizações sociais que atuam nas cadeias de valor do açaí em Carauari.

O projeto foi submetido, previamente, ao Comitê de Ética em Pesquisa da Universidade Federal do Amazonas, obtendo registro CAAE: 69381817.5.0000.5020 e parecer favorável de número 2.184.046. Para as coletas de dados, na RESEX Médio Juruá, foi obtida a inscrição, junto ao Sistema de Autorização e Informação em Biodiversidade - SISBIO no № 59770. Para a coleta de dados na RDS de Uacari foi obtida a autorização № 73/2017 -DEMUC/SEMA.

\section{Resultados e Discussão}

Caracterização dos solos dos açaizais em Carauari

Entre os fatores para a eco-organização dos açaizais nos ambientes, está a capacidade para o estabelecimento de lógicas circulares, onde o sistema é capaz de se sustentar em virtude de uma rede conectada no subsolo, com uma séria de reações metabólicas que, continuamente, regeneram os componentes a partir do ingresso de nutrientes e de energia vindos de fora (input), bem como do feedback do descarte (output) de produtos ou serviços no ambiente (CAPRA e LUISI, 2014).

Os três territórios de Carauari apresentam solos predominantes, do tipo Argissolo VermelhoAmarelo Alítico (IBGE, 2010), que são solos que ocorrem em áreas de relevos mais acidentados e dissecados, sendo as principais restrições relacionadas à fertilidade e susceptibilidade à erosão (SANTOS et al.,2018).

Os solos analisados são alíticos, ou seja, indicaram teores elevados de alumínio, alta acidez (com uma média do pH de 3,8), elevada saturação de alumínio (todas as amostras acima de 90\%), além do teor baixo de fósforo (com exceção do solo de Pupuaí). As amostras apresentaram, ainda, baixo teor de cálcio, magnésio e matéria orgânica (Tabela 1). A média da concentração de alumínio foi de 5,3, e do potássio chegou a 28,3 . 
Tabela 1. Análises químicas das amostras de solos coletadas nos açaizais existentes nos diferentes territórios pesquisados em Carauari - AM, nos anos 2016/2017.

\begin{tabular}{|c|c|c|c|c|c|c|c|c|}
\hline \multirow[b]{2}{*}{ Análises Químicas* } & \multicolumn{5}{|c|}{$\begin{array}{c}\text { RESEX } \\
\text { MÉDIO JURUÁ } \\
\end{array}$} & \multirow{2}{*}{ 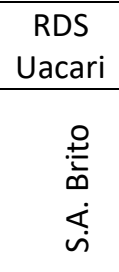 } & \multicolumn{2}{|c|}{$\begin{array}{c}\text { PA } \\
\text { RIOZINHO } \\
\end{array}$} \\
\hline & 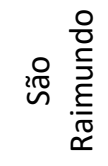 & $\begin{array}{l}\frac{\pi}{2} \\
\frac{0}{3} \\
0\end{array}$ & $\begin{array}{l}\frac{0}{\frac{1}{0}} \\
\frac{0}{\sqrt{0}} \\
\frac{0}{1}\end{array}$ & $\stackrel{0}{0}_{2}^{0} \stackrel{?}{\frac{\pi}{2}}$ & 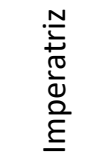 & & 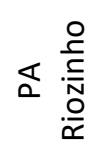 & 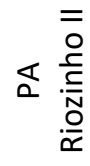 \\
\hline $\mathrm{pH}(\mathrm{CaCl})$ & 3,7 & 3,8 & 3,8 & 3,7 & 3,8 & 3,6 & 3,8 & 4 \\
\hline $\mathrm{H}+\mathrm{Al}\left(\mathrm{cmolc} \mathrm{dm}^{-3}\right)$ & 7,6 & 6,6 & 6,6 & 11,9 & 8,6 & 10,6 & 7,7 & 5,8 \\
\hline$P(m g d m)$ & 3 & 15 & 2 & 3 & 2 & 1 & 2 & 2 \\
\hline $\mathrm{K}(\mathrm{mgdm})$ & 48 & 32 & 24 & 28 & 48 & 14 & 22 & 10 \\
\hline $\mathrm{Al}\left(\mathrm{cmol} \mathrm{dm^{-3 } )}\right.$ & 4,4 & 3,6 & 5,2 & 9,2 & 5,5 & 8,5 & 4,1 & 2 \\
\hline $\mathrm{Ca}\left(\mathrm{cmol} \mathrm{dm} \mathrm{dm}^{-3}\right)$ & 0,15 & 0,15 & 0,15 & 0,2 & 0,2 & 0,2 & 0,1 & 0,1 \\
\hline $\mathrm{Mg}\left(\mathrm{cmol} \mathrm{dm}^{-3}\right)$ & 0,05 & 0,1 & 0,1 & 0,1 & 0,1 & 0,1 & 0,05 & 0,05 \\
\hline $\mathrm{MO}\left(\right.$ dag kg$\left.^{-1}\right)$ & 1,8 & 1,1 & 1 & 1,2 & 2,6 & 1,1 & 1,6 & 1,2 \\
\hline $\mathrm{t}\left(\mathrm{cmolc} \mathrm{dm}^{-3}\right)$ & 4,72 & 3,93 & 5,51 & 9,57 & 5,92 & 8,84 & 4,31 & 2,18 \\
\hline $\mathrm{T}\left(\mathrm{cmolc} \mathrm{dm}^{-3}\right)$ & 7,92 & 6,93 & 6,91 & 12,27 & 9,02 & 10,9 & 7,91 & 5,98 \\
\hline $\mathrm{SB}\left(\mathrm{cmolc} \mathrm{dm}^{-3}\right)$ & 0,32 & 0,33 & 0,31 & 0,37 & 0,42 & 0,34 & 0,21 & 0,18 \\
\hline V (\%) & 4,08 & 4,79 & 4,51 & 3,03 & 4,69 & 3,07 & 2,61 & 2,94 \\
\hline m (\%) & 93,16 & 91,56 & 94,35 & 96,12 & 92,86 & 96,2 & 95,2 & 91,9 \\
\hline
\end{tabular}

${ }^{*} \mathrm{pH}=$ Acidez ativa; $\mathrm{H}+\mathrm{Al}=\mathrm{Acidez}$ potencial (SMP); $\mathrm{P}=$ Fósforo (Mehlich-1); $\mathrm{K}=$ Potássio (Mehlich-1); $\mathrm{Al}=$ Alumínio (KCl); $\mathrm{Ca}=\mathrm{Cálcio} \mathrm{(KCl);} \mathrm{Mg} \mathrm{=}$ Magnésio $(\mathrm{KCl}) ; \mathrm{MO}=$ Matéria orgânica (colorimetria); $\mathrm{t}=$ Cap. de troca de cátions efetiva; $\mathrm{T}=$ Cap. de troca de cátions a $\mathrm{pH} 7 ; \mathrm{SB}=\mathrm{Soma}$ de bases; $V$ = Saturação por bases; $m$ = Saturação por alumínio.

As análises indicam que o teor de nutrientes do solo não é um bom indicador do fluxo absorvido pelas raízes, nem mesmo para a maioria dos nutrientes limitantes. Autores como Sardans e Peñuelas (2015) discutem que as árvores que crescem em solos com disponibilidade baixa de fósforo podem desenvolver mecanismos adaptativos de longo prazo, para armazenar esse elemento na biomassa. Isso está de acordo com Heineman et al. (2016), que sugeriram que espécies tropicais podem estar sob seleção para alocar excesso de armazenamento para mitigar a limitação de fósforo, quando das exigências de crescimento da planta exceder a oferta do solo. Segundo Grau et al. (2017), a reabsorção de nutrientes e o armazenamento de grandes quantidades desses nutrientes limitantes, em florestas com elevada biomassa, podem ser um mecanismo plausível para contrabalançar a baixa disponibilidade no solo e para reduzir a dependência em relação à absorção direta.

As análises indicam características comuns para os solos dos trópicos úmidos. No entanto, a tese da homogeneidade dos solos amazônicos tem sido, nas últimas décadas, cada vez mais questionada. Os solos da Amazônia são variados. Eles podem ser considerados (paradoxalmente) como os mais pobres e os mais ricos do mundo (manchas de terras pretas de índio). Esses resultados corroboram com os dados observados por Oliveira et al. (2015) e Wadt et al. (2015) para diversas áreas na Amazônia.

Esses resultados sugerem que as estratégias fisiológicas, principalmente da espécie $E$. precatoria, em seu processo de auto-organização, permitem sua plena estruturação nas paisagens do Médio Juruá. A maioria das espécies tropicais cresce em solos antigos e ácidos, em regiões com alta precipitação mensal (> $100 \mathrm{~mm}$ ) por, pelo menos, uma parte do ano (GRAU et al. , 2017). A lixiviação de nutrientes durante um longo período reduz drasticamente o conteúdo de nutrientes nos solos (VITOUSEK et al., 2010), o que sugere estratégias sistêmicas na fisiologia vegetal dessas espécies.

Outros aspectos relevantes na manutenção da estrutura local dos açaizais estão relacionados com a alta interação entre os componentes da biodiversidade, sua considerável umidade e exposição ao sol durante todo o ano.

A estrutura populacional dos açaizais em Carauari

Os ambientes de desenvolvimento das palmeiras de açaí, nos três territórios estudados, estão distribuídos em áreas de terra firme e em áreas alagáveis nas várzeas do rio Juruá. No Assentamento Riozinho, a produção se dá em terra firme, onde os açaizais ocorrem na forma de plantios, em sistemas 
consorciados de diferentes espécies de açaís ou, ainda, plantios em sistema agroflorestal (SAF), com espécies vegetais (arbóreas e agrícolas) e criação de animais (aves, porcos, boi, etc). Quanto às espécies de açaí, foram registrados plantios de Euterpe precatoria Mart. e Euterpe oleraceae Mart., ocorrendo uma miscelânea entre as espécies nos sistemas produtivos cultivados.

No interior da Reserva Extrativista Médio Juruá e da Reserva de Desenvolvimento Sustentável de Uacari, foram registrados açaizais em ambientes naturais de baixio. As áreas de baixios mencionadas neste artigo tratam-se das áreas mais baixas de topografia do terreno, nas proximidades dos igarapés no interior da floresta de terra firme. Nessas áreas, a vegetação é classificada como Floresta Ombrófila Densa Aluvial Dossel Emergente e Floresta Ombrófila Aberta Aluvial com Palmeiras (IBGE, 2012). Esses açaizais são aglomerados de palmeiras da espécie E. precatoria Mart, os quais, segundo relatos de produtores locais, guardam características de ação antrópica nas suas constituições no passado, sejam elas antigas ocupações por comunidades indígenas ou não indígenas.

Os açaizais, tanto nas áreas de cultivo na sede de Carauari, como nas áreas de floresta extrativa nas unidades de conservação, estão em complementariedade com os maciços florestais adjacentes, fato esse que garante a geração de renda, associado à manutenção dos serviços ecológicos.

Os aglomerados de Euterpe se estruturam no ambiente no Médio Juruá, por meio de interações recorrentes de input e output, de onde partem as emergências que determinam as características essenciais do sistema ambiental.

Nas áreas de cultivo de açaí, localizadas no Assentamento Riozinho, foram realizados os registros de indivíduos de Euterpe precatoria Mart., e Euterpe oleraceae Mart. Nas florestas extrativas da Reserva Extrativista Médio Juruá e da Reserva de Desenvolvimento Sustentável de Uacari, todos os indivíduos inventariados pertencem à espécie E. precatoria Mart., pois, nessas áreas, não há ocorrência nativa de E. oleraceae (OLIVEIRA, et al., 2000).

Nos quatro hectares inventariados em Carauari, foram registrados 1.486 indivíduos de Euterpe spp. Nas 16 subparcelas inventariadas, verificou-se que a média geral é de 371 ind.ha-1 ${ }^{-1}$. Nos sistemas em cultivos agrícolas, a média foi de 498 ind.ha ${ }^{-1}$, enquanto nas florestas extrativas, a média foi de 246 ind.ha-1 (Tabela 2). A quantidade registrada nas áreas extrativas foi superior ao encontrado por Rocha e Viana (2002) para áreas de floresta no Estado do Acre, porém, inferior aos registros de Martinot et al., (2017), para floresta extrativa no município de Manacapuru, no estado do Amazonas.

Embora as áreas de cultivo apresentem uma maior densidade, com uma quantidade de 995 ind.ha-1, o que facilitaria o trabalho de coleta, sua produtividade por planta apresentou-se menor que as das florestas extrativas, que apresentou somente 491 ind.ha $^{-1}$. O sistema cultivado, de forma agroflorestal, apresentou as vantagens de resultar em plantas mais baixas, com maior densidade (697 ind.ha-1) e menor frequência de indivíduos sem cacho, com uma produção superior a do cultivo em consórcio, que apresentou apenas 298 ind.ha $^{-1}$ (Tabela 2).

Tabela 2. Densidade, área basal, médias e desvio padrão (DP) de altura e DAP e média de número de cachos por estipe de Euterpe precatoria e Euterpe oleracea em diferentes açaizais do município de Carauari-AM, nos anos $2016 / 2017$.

\begin{tabular}{|c|c|c|c|c|c|c|}
\hline Território & $\begin{array}{c}\text { Caracterização } \\
\text { da área }\end{array}$ & $\begin{array}{c}\text { Densidade } \\
\text { absoluta } \\
\text { (n. }{ }^{\circ} \text { de } \\
\text { indivíduos/ha) }\end{array}$ & $\begin{array}{c}\text { Área Basal } \\
\left(\mathrm{m}^{2} / \mathrm{ha}\right)\end{array}$ & $\begin{array}{c}\text { Altura } \\
\text { média (m) e DP }\end{array}$ & $\begin{array}{c}\text { DAP } \\
\text { média }(\mathrm{cm}) \text { e DP }\end{array}$ & $\begin{array}{c}\text { Cachos } \\
\text { (n. }{ }^{\circ} \text { de } \\
\text { cachos/estipe) }\end{array}$ \\
\hline $\begin{array}{c}\text { PA } \\
\text { Riozinho }^{1}\end{array}$ & $\begin{array}{l}\text { Plantio em } \\
\text { Consórcio }\end{array}$ & 298 & 5,28 & $10,38 \pm 2,18$ & $13,05 \pm 3,99$ & 1 \\
\hline $\begin{array}{c}\text { PA } \\
\text { Riozinho }{ }^{1}\end{array}$ & $\begin{array}{c}\text { Sistema } \\
\text { Agroflorestal }\end{array}$ & 697 & 13,05 & $6,23 \pm 1,95$ & $12,41 \pm 3,43$ & 2 \\
\hline $\begin{array}{l}\text { RESEX } \\
\text { Médio } \\
\text { Juruá }{ }^{2}\end{array}$ & $\begin{array}{l}\text { Floresta } \\
\text { Extrativa }\end{array}$ & 163 & 3,06 & $10,79 \pm 3,21$ & $15,92 \pm 3,61$ & 2 \\
\hline $\begin{array}{l}\text { RDS de } \\
\text { Uacari }^{2}\end{array}$ & $\begin{array}{l}\text { Floresta } \\
\text { Extrativa }\end{array}$ & 328 & 5,73 & $9,82 \pm 3,65$ & $14,96 \pm 3,11$ & 1 \\
\hline \multicolumn{2}{|c|}{ Média } & 371 & 6,80 & 9,30 & 14,08 & 1,5 \\
\hline
\end{tabular}


${ }^{1}$ Inventário realizado com indivíduos de E. precatoria (possui estipe único) e E. oleracea (possui perfilhamento abundante, formando touceira com estipes em diferentes estádios., As médias em Altura, DAP e $\mathrm{N}^{\circ}$ de cachos se dão por estipe). PA Riozinho = Projeto de Assentamento Riozinho; ${ }^{2}$ Ambiente inventariado somente com indivíduos da espécie E. precatória. RESEX = Reserva Extrativista, RDS = Reserva de Desenvolvimento Sustentável.

A densidade de palmeiras nos cultivos em Carauari foi, aproximadamente, duas vezes maior do que na floresta extrativa. Assim, nas áreas agrícolas, a produção e o trabalho de coleta podem ser concentrados em uma área menor, com redução do esforço e aumento significativo do rendimento do trabalho.

Com relação às espécies de Euterpe, nas áreas agrícolas no Assentamento Riozinho, a diferença entre as quantidades plantadas indica que os produtores em Carauari possuem preferência em cultivar o açaí da mata (E. precatoria Mart.), em relação ao açaí de planta (como é chamado localmente a $E$. oleraceae Mart). No SAF, o açaí da mata representou uma porcentagem de $77 \%$, já no sistema consorciado, os indivíduos dessa espécie representaram $75 \%$ dos plantios.

Nas florestas extrativas de Carauari, durante a safra, o açaizeiro da mata (E. precatoria Mart.) produz entre dois e seis cachos. Um hectare de terra firme pode produzir mais de 140 quilos de frutos e, em áreas de baixio, a produção pode atingir mais de 270 quilos por hectare. Apesar disso, os açaizeiros mais explorados são aqueles de terra firme, próximos aos corpos d'água, pois seus cachos são maiores. Uma palmeira de baixio produz, em média, 7,5 quilos de frutos, enquanto uma palmeira de terra firme produz 8,5 quilos (FERREIRA, 2005).

As florestas extrativas da região, como indicado pelos resultados de densidade, estrutura, dinâmica e a estabilidade populacional da espécie Euterpe precatoria, apresentam características ecológicas favoráveis para o manejo sustentável, da mesma forma como já foi assinalado por Rocha (2004) e Ribeiro (2014), para florestas com açaizais no Acre, Rondônia e outras áreas da Amazônia Central.

Comparando as alturas das palmeiras de Euterpe nas áreas agrícolas no Assentamento Riozinho, foi observado que os indivíduos E. oleraceae foram os mais altos, sendo o açaizal no SAF com palmeiras menores (média de $6 \mathrm{~m}$ ) que as palmeiras no sistema consorciado (média de 10m). Nas duas florestas extrativas e no cultivo em consórcio, a média da altura para E. precatoria foi de, aproximadamente, $10 \mathrm{~m}$, enquanto no SAF, os indivíduos dessa espécie obtiveram médias próximas de $6 \mathrm{~m}$ (Tabela 2). As palmeiras de açaí apresentam menor crescimento em altura e diâmetro quando estão dispostas em cultivos em SAF. Para a realização da coleta do açaí, a menor altura das árvores facilita a eficiência no trabalho.

Os ambientes de produção de açaí influenciam, de forma direta, no desenvolvimento dos indivíduos. Essa relação pode ser percebida quando, por exemplo, analisamos os dados de altura com a circunferência do estipe das palmeiras. Quando se observa os dados de todos os indivíduos inventariados em um gráfico, é possível perceber três concentrações nas disposições dos valores (Figura 2). 


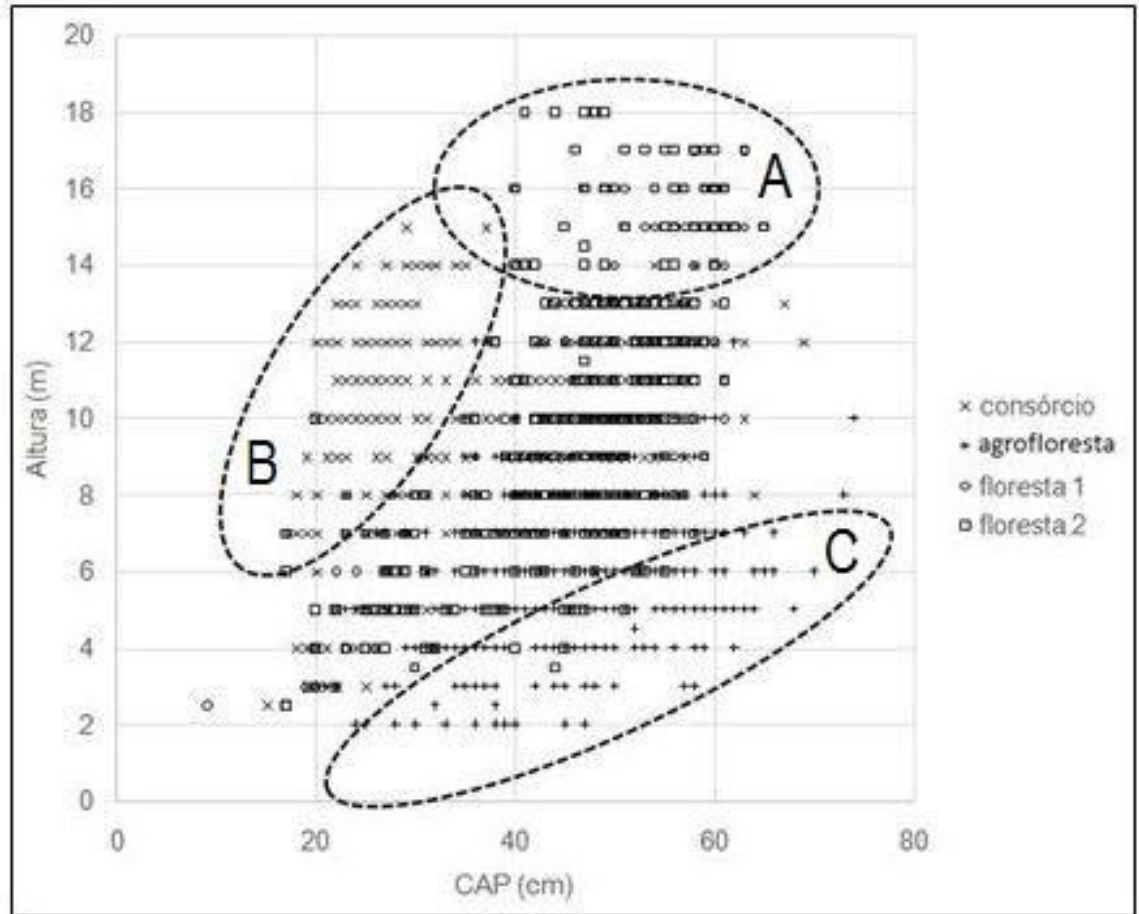

Figura 2. Gráfico de dispersão da relação entre as alturas $(m)$ com as circunferências $(\mathrm{cm})$ dos estipes das palmeiras de açaí inventariados nos diferentes territórios em Carauari, AM, nos anos de 2016/2017.

O primeiro agrupamento de valores identificado no gráfico de dispersão ocorre na relação entre a altura e a circunferência dos estipes no ambiente de floresta extrativa existente na Reserva de Desenvolvimento Sustentável de Uacari (Figura 2: círculo A). Nesse território, o inventário amostral foi realizado na Comunidade Vila Ramalho. $\mathrm{O}$ açaizal de uso dos agroextrativistas locais encontra-se no interior da Comunidade, próximo das casas. As palmeiras competem entre si e com outras espécies, no espaço denominado, localmente, como quintal ou terreiro. As palmeiras, neste ambiente, caracterizamse por serem mais altas (14 a 18m) e possuírem uma circunferência mediana, entre 40 a $60 \mathrm{cmde}$ diâmetro de seus estipes.

A segunda concentração, para os valores das palmeiras de açaí, está no ambiente de consórcio de Euterpe, das áreas agrícolas no Assentamento Riozinho (Figura 2: círculo B). Nesse, a maioria dos indivíduos possui uma altura entre 6 a 14 metros e estipes mais finos. Tal fato pode representar 0 resultado da competição entre os açaizeiros por maior luminosidade.

O terceiro ambiente de concentração de palmeiras de açaí está localizado no cultivo, em sistema agroflorestal, também presente nas áreas do Assentamento Riozinho, próximo à sede de Carauari, (Figura 2: círculo C). Esses indivíduos possuem como característica menor desenvolvimento em altura e boa parte com diâmetros dos estipes maiores em relação às outras concentrações de palmeiras.

Açaizais associados aos agroecossistemas

No Projeto de Assentamento Riozinho, entre os anos de 2016 e 2017, existiam, aproximadamente, 200 produtores rurais. As principais fontes de renda no Assentamento Riozinho eram oriundas dos processos produtivos, desenvolvidos nos agroecossistemas locais, além de benefícios sociais, como bolsa família e aposentadoria.

No Assentamento, inicialmente foram implantadas culturas como açaí, banana, café, coco, laranja e cupuaçu. Essas culturas ainda hoje são encontradas nas áreas, no entanto, culturas como banana e café encontram-se em menor número. Segundo relatos dos moradores locais, esse fato se deu pela falta de assistência técnica e baixo desempenho das mudas adquiridas na época.

Nos agroecossistemas do Assentamento Riozinho, foram identificadas 10 (dez) culturas que, junto com o açaí, constituem as paisagens produtivas nas áreas do Assentamento. Entre as culturas de maior importância na constituição dos agroecossistemas do Riozinho, destacam-se o açaí, a mandioca, o abacaxi, o cupuaçu, a manga e a pupunha.

Todos os produtos são destinados, a priori, para consumo das famílias, no entanto, uma parte desses possuem diferentes destinos, segundo as estratégias adotadas pelos agentes sociais locais para a geração de renda no mercado local. 
O trabalho nos açaizeiros está associado ao manejo de outras espécies e à percepção do desenvolvimento das palmeiras nos diferentes ambientes. Esse aspecto, em particular, demonstra que os produtores de açaí, ao longo do tempo, vão ampliando sua percepção frente ao manejo do ambiente. Tais resultados corroboram com observações de Brondízio (2009), que afirma que a implantação e manejo do açaí em sistemas cultivados requerem ações claras de agricultura especializada e trabalho florestal para manter e elevar a produtividade da colheita.

Os produtores agroextrativistas da Reserva Extrativista Médio Juruá e da Reserva de Desenvolvimento Sustentável de Uacari possuem forte vínculo com as organizações de bases locais, que atuam no fomento das atividades produtivas, na organização social e na infraestrutura das comunidades, sendo elas, a Associação de Produtores Rurais de Carauari (ASPROC), a Cooperativa de Desenvolvimento Agroextrativista e de Energia do Médio Juruá (CODAEMJ), e a Associação dos Moradores Agroextrativistas da Reserva de Desenvolvimento Sustentável de Uacari (AMARU).

As principais fontes de renda, nas comunidades pesquisadas na Reserva Extrativista, são oriundas dos processos produtivos, desenvolvidos nos agroecossistemas locais, além de benefícios sociais, como bolsa família, bolsa verde e aposentadoria. Entre as diversas atividades desenvolvidas nos agroecossistemas locais, destacaram-se, na geração de renda, a produção de farinha de mandioca, açaí, banana, sementes de murumuru e andiroba, pirarucu, borracha natural e peixes diversos.

Os produtos da agricultura convergem em grande parte para consumo das famílias agroextrativistas, no entanto, parte dessa produção é comercializada, tanto nos mercados, dentro dos territórios geográficos, como fora dos territórios, destinada à geração de renda. Os produtos do extrativismo, com exceção do açaí, são coletados e comercializados diretamente no mercado no território, junto às organizações, como a ASPROC e CODAEMJ.

$O$ fruto do açaí produzido nos agroecossistemas da RESEX Médio Juruá possui três vias de destino, sendo a primeira para consumo nas famílias produtoras. A segunda via é a distribuição entre os vizinhos na comunidade, ato denominado localmente de "vizinhar". Dessa forma, a Comunidade corresponde ao universo social, no qual as famílias realizam transações de trocas não monetárias (por relações de reciprocidade) e fortalecem laços culturais. A terceira via é a comercialização com o mercado convencional, representado por atravessadores nos portos das comunidades, ou nos escoamentos da produção até a agroindústria na sede do município. Existe, ainda, a comercialização junto aos batedores artesanais de açaí e consumidores de Carauari.

Além do extrativismo vegetal não madeireiro, outras atividades concorrem para a formação da renda bruta das famílias das comunidades da Reserva Extrativista Médio Juruá, como a agricultura e a pesca. A pluriatividade no uso do ambiente garante aos agroextrativistas moradores da Reserva Extrativista sua segurança alimentar e a geração de renda, além de permitir a manutenção dos serviços ecológicos e da biodiversidade associada (ciclagem de nutrientes, promoção de microclimas favoráveis, economia hídrica, regulação de populações de insetos-praga e organismos patogênicos, etc.).

Os principais produtos dos agroecossistemas da Reserva de Desenvolvimento Sustentável de Uacari são: a farinha de mandioca e de macaxeira, o fruto do açaí, a semente da andiroba, a semente de murumuru, as pranchas de borracha natural, a batata doce, o milho e o peixe.

As características de produção na Reserva de Desenvolvimento Sustentável e sua infraestrutura disponível são, praticamente, as mesmas da Reserva Extrativista, pois, além de estarem geograficamente muito próximas (o rio Juruá separa as duas unidades de conservação, sendo na margem esquerda a RESEX e na margem direita a RDS). Também possuem acesso à terra, por meio de concessões de uso, acesso à saneamento básico (Projeto Sanear Amazônia de gestão da ASPROC), além de desfrutar dos produtos e serviços da biodiversidade, associada as suas florestas.

O mercado, nas duas unidades de conservação, vincula-se ao agroecossistema, a partir de fluxos de saída, seu output, e no feedback, por meio das mensagens emitidas pelos agentes sociais e no seu valor de troca. Configura-se, assim, um sistema aberto que se alimenta de matéria e energia extraída do ambiente, onde seu estilo de gestão promove uma reprodução relativamente autônoma e historicamente garantida (PLOEG, 1993), pois as famílias possuem o controle dos recursos mobilizados para o processo produtivo de beneficiamento.

As relações que os agroextrativistas estabelecem com seu ambiente cotidiano na Reserva de Desenvolvimento Sustentável de Uacari e na Reserva Extrativista Médio Juruá corroboram com autores (FRAXE, 2004; NODA, 2007; PEREIRA et al., 2015), que relacionam a pluriatividade de suas práticas 
produtivas com um saber associado, sendo esse utilizado como uma poderosa estratégia, que permite a apropriação de métodos de uso dos recursos naturais/bens comuns benéficos à conservação da biodiversidade. Esse saber, muitas vezes, é transmitido de pais para filhos, atravessa gerações e contribui para uma relação harmoniosa e complementar entre o homem e a natureza (DIEGUES et al., 2000).

Os agroecossistemas na Reserva Extrativista Médio Juruá e na Reserva de Desenvolvimento Sustentável de Uacari funcionam como sistemas sociais vivos afastados do equilíbrio, pois não existem apenas no domínio físico, mas também em um domínio social simbólico, modelado pelo "mundo interior" dos conceitos, ideias e símbolos, que surgem a partir da consciência do "viver coletivamente", a partir de convenções sociais estabelecidas por, segundo Capra e Luisi (2014, p. 380), constructos flexíveis e continuamente renegociados.

Os moradores da Reserva Extrativista e da Reserva de Desenvolvimento Sustentável mantêm uma relação histórica com o uso da floresta, principalmente para a prática do extrativismo (DERICKX, 1993; ITABORAHY, 2009). O manejo do açaí nas áreas é uma expressão desse uso conservacionista dos recursos florestais. Os resultados dos levantamentos sugerem que as comunidades ribeirinhas e de agricultores familiares tradicionais de Carauari, assim como outras populações amazônicas do passado e do presente (BALÉE et al., 2020), continuam interagindo em processos ecológicos naturais, e moldando a distribuição de plantas e paisagens florestais na região.

Já os moradores do Assentamento Riozinho, buscam inovar a relação ancestral, ao promoverem um processo de intensificação da produção, mediante a ampliação das áreas de cultivo. A seleção massal e o manejo das plantas em ambientes alterados são uma modificação do processo ancestral de domesticação da espécie e, no longo prazo, sua continuidade poderá levar ao surgimento de variedades melhor adaptadas ao ambiente domesticado.

A produção de açaí em Carauari vai ao encontro do que preconizam pesquisadores como Bertha Becker (2013), sobre a perspectiva conservacionista (endógeno) e desenvolvimentista (exógena), que caracterizam alguns dos projetos para a região amazônica, e que refletem interesses econômicos e políticos diversos. O primeiro, prioriza ações e políticas ambientais, e valoriza as populações humanas locais, enquanto o exógeno favorece a infraestrutura voltada ao desenvolvimento técnico-industrial. Com os resultados expostos corroboramos com Becker (2013), quando afirma que é perfeitamente possível desenvolver sem destruir maciçamente a natureza e contemplar igualmente a articulação dos territórios com as populações regionais.

Os sistemas de produção extrativo e de cultivo estão na base das decisões tomadas pelas comunidades na condução dos processos produtivos do açaí, tendo, ainda, uma fundamental influência na forma como são percebidas e interpretadas as relações sociais entre os indivíduos nos diferentes lugares.

\section{Considerações Finais}

No Médio Juruá, a caracterização agroecológica dos açaizais investigados assume seu valor nas áreas de uso, a partir de suas propriedades emergentes e complementares no ambiente. Não podem ser reduzidas às propriedades das partes, mas, sim, de sua interação no sistema. A produção do açaí se estabelece a partir de uma interação com a biodiversidade local e a agricultura desenvolvida no âmbito familiar. As análises dos solos indicaram características de baixa fertilidade química e alta acidez, típicas de solos da região amazônica. Quanto às diferenças estruturais nas áreas de produção do fruto entre as áreas extrativas e de cultivo, embora essas últimas possam ter apresentado uma maior densidade, o que facilitaria o trabalho de coleta, sua produtividade por planta pode ser menor que a da floresta extrativa. O sistema agroflorestal é mais promissor, uma vez que resulta em plantas mais baixas, com maior densidade por área, com menor frequência de indivíduos, sem cacho e com uma produção superior à do monocultivo de açaí. Por isso, recomendam-se os plantios em SAF, como melhor alternativa para intensificação da produção de açaí, em complementariedade à conservação das florestas. O manejo dos açaizais, em Carauari, apresenta-se como um processo de socialização da natureza, com argumentos positivos para uma ética ambiental, fundada por princípios de manutenção ecológica e cultural. 
Agradecimentos

A todo corpo docente e discente do Programa de Pós-Graduação em Ciências do Ambiente e Sustentabilidade na Amazônia. Ao Programa Pró-Amazônia: Biodiversidade e Sustentabilidade (CAPES) e à Universidade Federal do Amazonas, pelo apoio financeiro. Pela contribuição técnica e colaboração humana, agradeço ao Núcleo de Etnologia na Amazônia Brasileira (NETNO), à Rede de Estudo em Agroecossistemas Amazônicos, ao Núcleo de Socioeconomia (NUSEC) e ao Instituto Acariquara Organização de Serviços Socioambientais Sustentáveis.

\section{Referências Bibliográficas}

BALÉE, W. Cultural forests of the Amazon. Garden, v. 11, n. 6, p. 12-14, 1987.

BALÉE, W.; de OLIVEIRA, V.H.; dos SANTOS, R. et al. Ancient Transformation, Current Conservation: Traditional Forest Management on the Iriri River, Brazilian Amazonia. Hum Ecol (2020). <https://link.springer.com/article/10.1007\%2Fs10745-020-00139-3> Acesso em: 25 mar.de 2020.

BECKER, B.K. Revisão das políticas de ocupação da Amazônia: é possível identificar modelos para projetar cenários? Parcerias Estratégicas, 12, p.135-159, 2001.

BECKER, B. K. A Urbe Amazônida. Rio de Janeiro: Ed. Garamond, 2013.

BRONDÍZIO. E. S. Análise Intra-Regional de Mudanças do Uso da Terra na Amazônia. In: Ecossistemas Florestais: Interação homem-ambiente. São Paulo, Ed SENAC. Edusp. 2009

CAPRA, F.; LUISI, P. L. A Visão Sistêmica da Vida: Uma Concepção Unificada e suas Implicações Filosóficas, Políticas, Sociais e Econômicas. Ed. Cultrix, Amana-Key. São Paulo-SP. 615 p. 2014.

DERICKX, J. No coração da Amazônia: Juruá, o rio que chora. Ed. Vozes. Rio de Janeiro, 1993.

DIEGUES, A. C. et al. Os Saberes Tradicionais e a Biodiversidade no Brasil. São Paulo: MMA/Cobio/Nupaub/USP, 2000.

FERREIRA, E. Açaí Solteiro. In: SHANLEY, P; MEDINA, G. (Orgs.). Frutíferas e plantas úteis na vida amazônica. Belém: CIFOR, Imazon, 2005.

FRAXE, Theresinha de J. P. Cultura cabocla-ribeirinha: mitos, lendas e transculturalidade. São Paulo: Annablume, 374p. 2004.

GRAU, O.; PENUELAS, J.; FERRY, B.; FREYCON, V.;BLANC, L.; DESPREZ, M.; BARALOTO, C.; CHAVE, J.; DESCROIX, L.; DOURDAIN, A.; GUITET, S.; JANSSENS, I.A.; SARDANS, J.; HÉRAULT, B. Nutrient-cycling mechanisms other than the direct absorption from soil may control forest structure and dynamics in poor Amazonian soils. Scientific Reports. 7:45017 | DOI: 10.1038/srep45017. 2017. Disponível em: <https://www.nature.com/articles/srep45017.pdf> Acesso em: 15 jan.2018.

HEINEMAN, K. D., TURNER, B. L; DALLING, J. W. Variation in wood nutrients along a tropical soil fertility gradient. New Phytol.doi: 10.1111/nph.13904. 2016.

IBGE. MAPAS. Estado do Amazonas. Pedologia. Mapa Exploratório de Solos. 2010

IBGE. Manual Técnico da Vegetação Brasileira. Manuais Técnicos em Geociência Número 1. 2012.

IBGE. Produção da Extração Vegetal e da Silvicultura. 2015. Disponível em: https://sidra.ibge.gov.br/tabela/289\#resultado. Acesso em Nov. 2015

ITABORAHY, W. Terras, Florestas, Barcos e Barracões. Dissertação (Mestrado em Ciências) Curso de PósGraduação Desenvolvimento, Agricultura e Sociedade. Universidade Federal Rural do Rio de Janeiro. Rio de Janeiro. 2009

LEVIS, C.; FLORES, B. M; MOREIRA, P. A.; LUIZE, B. G.; ALVES, R. P.; FRANCO-MORAES, J. ; LINS, J.; KONINGS, E. ; PEÑA-CLAROS, M. ; BONGERS, F. ; COSTA, F. R. C. ; CLEMENT, C. R. How People Domesticated Amazonian Forest. Frontiers in Ecology and Evolution. Vol. 5. Article 171. Jan 2018. Disponível em: $<$ https://www.researchgate.net/publication/322567017 How People Domesticated Amazonian Forests $>$ Acesso em: 03 jun. 2018.

MAGALHÃES, M. P. (org). Amazônia Antropogênica. Museu Paraense Emílio Goeldi. Belém-PA, 429p. 2016

MARTINOT, J. F. Manejo Agroextrativista do açai-da-mata na Amazônia Central. Dissertação de mestrado. PPGCASA. UFAM. 120p. 2013.

MARTINOT, J. F., PEREIRA, H. S., SILVA, S. C. P. Coletar ou Cultivar: as escolhas dos produtores de açaí-da-mata (Euterpe precatoria) do Amazonas. Revista de Economia e Sociologia Rural. Vol. 55, № 04, p. 751-766. Out/Dez 2017.

MORAN, E. F. Adaptabilidade Humana: Uma Introdução à Antropologia Ecológica. Editora da Universidade de São Paulo, 512p. 2010.

NETTO, P. S. Plano de colonização do Alto Turi. Inventário Florestal. Curitiba: Centro de Pesquisas Florestais da UFPR, 238 p. 1971. 
NODA, S. N. Agricultura familiar na Amazônia das águas. Manaus-AM. Universidade Federal do Amazonas. 207p. 2007.

OLIVEIRA, R. R.; COELHO NETTO, A. L. Processos interativos homem-floresta na evolução da paisagem da Ilha Grande, RJ. Geo UERJ Revista do Departamento de Geografia, v. 8, p. 29-38, Rio de Janeiro, 2000.

OLIVEIRA, I. A. de; CAMPOS, M. C. C.; MARQUES JUNIOR, J.; AQUINO, R. E. de; TEIXEIRA, D. de B.; SILVA, D. M. P. da. Use of scaled semivariograms in the planning of soil chemical proprieties in Southern Amazonas, Brazil. Revista Brasileira de Ciência do Solo, 39(1): 31-39, 2015.

PEGLER, L. Peasent Inclusion in Global Valeu Chains: economic upgrading but social downgrading in labour processes? The Journal of Peasent Studies. Publishid online: 25 jun 2015. Disponível em: <https://www.tandfonline.com/doi/abs/10.1080/03066150.2014.992885?scroll=top\&needAccess=true\&journalCo de=fjps20. $>$ Acessado em: 29 jun. 2015.

PEREIRA, H. S.; VINHOTE, M.L.A.; ZINGRA, A. F. C.; TAKEDA, W. M. A Multifuncionalidade da Agricultura Familiar no Amazonas: Desafios para a Inovação Sustentável. (In) Terceira Margem Amazônia/Outras Expressões. v. 1, n. 5. São Paulo. 254p. 2015

PLOEG, J. D. van der. El proceso de trabajo agrícola y la mercantilización. In: SEVILLA GUZMAN, E.; GONZALEZ DE MOLINA, M. Ecología, campesinado e historia. Madrid: La Piqueta, 1993.

RIBEIRO, G. D. Açaí solteiro, açaí do Amazonas (Euterpe precatoria), uma boa opção de exploração agrícola em Rondônia. Revista Ambiente Brasil. Publicado online: 2014.

ROCHA, E.; VIANA. V. Aspectos ecológicos e sociológicos do manejo de Euterpe precatoria (açaí) no Acre - Brasil. Dissertação de mestrado. USP. Escola de Engenharia de São Paulo. 143p. 2002.

ROCHA, E. Potencial ecológico para o manejo de frutos de açaizeiro (Euterpe precatoria Mart.) em áreas extrativistas no Acre, Brasil. Acta Amaz. v. 34, n. 2, p. 237-250, Manaus, 2004 . Disponível em: <http://www.scielo.br/pdf/aa/v34n2/v34n2a11.pdf> Acesso em: 29 mai. 2011.

SANTOS, H. G. dos; ZARONI, M. J.; ALMEIDA, E. P. C. Árvore do Conhecimento. Solos Tropicais. Agência Embrapa de Informação tecnológica. $2018 . \quad$ Disponível em: <http://www.agencia.cnptia.embrapa.br/gestor/solos tropicais/arvore/CONT000gn0pzmhe02wx5ok0liq1mqk413 Ogy.html> Acesso em: 20 mar. 2018

SARDANS J. e PEÑUELAS J. Trees increase their P:N ratio with size. Glob. Ecol. Biogeogr. 24, 147-156. 2015.

SILVA, F. C. Manual de Análise Química de Solos, Plantas e Fertilizantes. Embrapa Informações Tecnológicas, (2) ed. rev. ampl. Brasília-DF: 627 p. 2009.

SIQUEIRA, J. A. S. A cadeia de valor do açaí: uma estratégia sistêmica na conservação dos agroecossistemas amazônicos no município de Carauari-AM. 2018. Tese de Doutorado. PPG-CASA. Universidade Federal do Amazonas, Manaus, 2018.

TRIOLA, F. M. Introdução à Estatística. 7. ed. Rio de Janeiro: LTC, 1999.

Van RAIJ, B.; ANDRADE, J.C.; CANTARELLA, H.; QUAGGIO, J. A. Análise Química para Avaliação da Fertilidade de Solos Tropicais. Campinas, Instituto Agronômico, 285p. 2001.

VITOUSEK, P. M., PORDER S., HOULTON B. Z.; CHADWICK, O. A. Terrestrial phosphorus limitation: mechanisms, implications, and nitrogen - phosphorus interactions. Ecol. Appl. 20, 5-15. 2010.

WADT, P. G. S, MIQUELONI, D. P.; SILVA, L. M.; OLIVEIRA Jr, R. C.; EVANGELISTA J. S.; WADT, L. H. O. Caracterização Espacial de Atributos de um Argissolo Vermelho-Amarelo da Floresta Amazônica no Estado do Acre. XXXV Congresso Brasileiro de Ciência do Solo. O Solo e Suas Múltiplas Funções. Natal-RN. 